\title{
Research on Developing and Survival Strategies of University Journals in New Media Age
}

\author{
Lihua Zhao \\ Editorial Department of Journal of Jilin Agricultural University, Changchun 130118, China \\ Zhaolihua2004@126.com
}

\begin{abstract}
Keywords: New media; University journal; Academic quality; Triditing System; Editors' quality; Gathering and editing system
\end{abstract}

\begin{abstract}
With the rapid development of science and technology, the new web-based digital media came into being. New media age posed a serious challenge to the survival and development of university journals. In order to improve the competitiveness of university journals, this paper analyzes the main reasons that influence the survival and development of university journals: low academic quality, excellent manuscript outflow, backward editing and publishing method, low editing and proofreading quality, long publishing period, timely information lag, closed running mode, low comprehensive quality of editors. This paper posed the developing and survival strategies of university journals in the new media age: intensifying topic selection and manuscript organization and trying to improve academic quality; reviewing carefully and checking academic quality; strengthen editing quality control and improving editing and proofreading quality; shortening publishing period and improving the timeliness of information; persisting in reform and innovation and broadening publicity channels; applying new media technologies and promoting the integrative development of university journals and new media; strengthening the editor group construction and improving the comprehensive quality of editors.
\end{abstract}

\section{Introduction}

With the rapid development of science and technology, the new web-based digital media came into being. The new media have developed on the basis of newspapers, books, radios, televisions and other traditional media. New media provide users with information and entertainment services in the form of propagation using digital technology, network technology and mobile technology, through the Internet, broadband and local area networks, wireless communication networks, satellite and other channels, as well as computers, mobile phones, digital televisions, etc. as the terminal [1]. New media age brings major changes in the channels that people obtain sci-tech information and more fierce competition between the sci-tech periodicals, which brings a serious challenge to the development of university journals, and traditional university journal publication concepts and models can not meet the requirements of the new media age. Therefore, this threatens the survival and development of university journals [2]. At present, the main reasons that affect the survival and development of university journals are low academic quality, excellent manuscript outflow, backward editing and publishing method, low editing and proofreading quality, long publishing period, timely information lag, closed running mode and low comprehensive quality of editors [3]. To deal with the challenge, the author suggests that university journals must carry out reform and innovation and the editors must change consciousness, must renew ideas, and improve abilities. In order to survive and develop, the following strategies must be adopted.

\section{Developing and Survival Strategies of University Journal in the New Media Age}

Intensifying Topic Selection and Manuscript Organization and Trying to Improve Academic Quality. Academic quality is the foundation of the survival and development of university journals [4]. The level of academic quality, first of all depends on the quality of topic selection. If the topic selection is inappropriate or unwise, no matter how well the subsequent work is done the required excellent quality journals can't be provided to the society because high level papers come from 
excellent topic selection. Just as other periodicals, topic selection and manuscript organization should grasp the current developing trend of a subject, seize the opportunity to reflect the latest achievements and give full play to its social and economic benefits. In order to achieve this goal, the editors must go into teaching and research office and society to contact teachers and researchers from different levels to discover and track breakthrough potential scientific research projects and plan to select the topic in the project in time. The projects are given priority based on their direction, significant social and economic benefits. University journals should widen the manuscript resource channels and increase the efforts of soliciting contributions for the excellent manuscripts. The so-called outstanding manuscripts are forward-looking, innovative, real and scientific. Academic quality of university journals ultimately depends on the quality of manuscripts and excellent manuscript is the fundamental guarantee of academic quality of university journals [5][6]. Therefore, to improve the academic quality of university journals, first of all university journals should pay close attention to the outstanding contributions and absorb them through various ways and channels, give full play to the role of editors and peer reviewers, track major and key scientific research projects. Manuscripts should be multi-directional and can't be limited to internal and external manuscript proportion. Soliciting contributions can come from manuscripts inside and outside universities, and also from domestic and abroad manuscripts.

Reviewing Carefully and Checking Academic Quality. Strictly implement “Triditing System”, and check academic quality from the source. Currently, university journal review system should be to simplify procedures, reduce duplication of effort and shorten the review period under the premise of guaranteeing the quality of review manuscripts. In accordance with this requirement, sci-tech journal of university should implement "Triditing System": editors review (preliminary examination), experts (including editorial board) review (examine and appraise), the chief editors or associate editors review (final manuscript). Persisting in "Triditing System" can check academic quality. In addition to the implementation of inside and outside review system, double-blind review system and other measures, submitting recommendation system can be implemented on the inside manuscripts. The introversion of university sci-tech journals makes academic editors and reviewers be interfered by personal relationships at checking academic quality. Therefore, we should impose constraints to the paper submission of inside authors, and this means when the authors submit papers, it is necessary to be with peers' comments. This is an important means of early paper quality control of university sci-tech journals. Through multi-constraints, increasing efforts of review to reduce manuscripts interfered by human relationship will help improve academic quality.

Strengthen Editing Quality Control and Improving Editing and Proofreading Quality. Editorial department should pay attention to the re-creation of editors in the process of dealing with manuscripts. When dealing with manuscripts, editors should consult with the authors over and over again, should process the content deeply to demonstrate the new ideas and development of outstanding research achievements and make the papers more closely demonstrated and organized more clearly according to the review advice and publishing requirement of the experts. At the same time, editors should strictly observe and fully implement the latest version of the national sci-tech periodical layout standardizations and normalizations. The implement of the standards is regarded as a main indicator for evaluating editors' performance. The level of the standard and regulation should be increased to meet the state standards and regulatory requirements from abstract, key words to references, from equation symbols, charts, quantities and units, digital review changing to character using. The editing and processing system, proofreading system (five-proofreading) of university journals and the job responsibilities of the editorial staff should be made and implemented strictly. The editors' responsibility system should be implemented in editing manuscripts. In order to reduce errors, editors in charge should be responsible for cross-proofreading, executive editors should be responsible for special proofreading and chief editors should be responsible for final proofreading.

Shortening Publishing Period and Improving the Timeliness of Information. Updating information in time is the timeliness of papers published in university journals, or paper publishing period. The publishing period has an important influence on the development of university journals. 
At present, there is a common problem of excessive delay of publication of university journals, which, to some extent, restricts the development of university journals and is the cause resulting in multiple contributions and excellent manuscript outflow. In order to shorten the publication cycle, university journals should be changed from quarterly to bimonthly, from bimonthly to monthly etc. to speed up the editing and publishing and improve the efficiency of publishing. Meanwhile, the number of published papers should be increased in each issue to increase the amount of information.

Persisting in Reform and Innovation and Broadening Publicity Channels. Competition between the sci-tech periodicals is fierce in the new media age. If journals do not publicize themselves, or promote themselves, it is difficult for them to be recognized by readers and authors, and will not be concerned about. Therefore, in order to expand the academic influence of university journals, increase reputation of university journals and accelerate the process of internationalization, journal editors will actively promote their publications, and intensify publicity to make domestic and foreign authors and readers understand the features and coverage scope of university journals. University journals should strengthen exchanges and cooperation with domestic and foreign outstanding journals to gain access to more important domestic and international retrieval systems and databases. First, university journals should actively present their current journals to main library at home and abroad, universities, research institutes of related disciplines literature search organization. Second, editors try to participate in academic conferences both at home and abroad and the annual meetings for journal editors, publicize and present journals to the participants to make more people understand the existence and development of the journal. Third, it is a quick, intuitive and economical way to promote the journal through the web[7]. Forth, channels of university sci-tech journal literature exchange with outside can be made full use of, university libraries should establish long-term stable cooperative relations with foreign retrieval system to publicize its own university journal.

Applying New Media Technologies and Promoting the Integrative Development of University Journals and New Media. With the development of computer technology and network technology, it is possible to provide more convenient services to the authors. Editorial Department can offer convenience for author submission, expert proofreading, editors modifying and authors' inquiring for manuscript processing etc. by building and improving its own website or using a professional manuscript gathering and editing system[8]. Editorial department should pay attention to the journal website construction and constantly enrich the amount of information of websites. Authors, readers, expert reviewers can have a more detailed understanding of the journals through the journal website. At the same time, resources can be best shared through the journal website platform.

Strengthening Editor Group Construction and Improving the Comprehensive Quality of Editors. The new media age provides the traditional scientific journals and editing methods with a new vitality and meaning, which brings the unprecedented test to university journals. With the development of new media technologies, this test becomes very severe, which puts forward new and higher requirements for the editors of university journals and the editors should increase their comprehensive quality and ability. Therefore, editors of sc-tech journals have to change their ideas, strengthen the sense of time and urgency, establish a modern editor consciousness and improve the ability to accept new things, which requires the editors of university sci-tech journals not only to have the quality and ability in the traditional sense, but also to supplement, update and optimize knowledge structure, and they must learn modern editing theories and technologies to improve the ability to obtain information [9]. In addition, the editors of university journals should also have a certain degree of research capacity, which is the requirement for proofreading, identifying and selecting manuscripts [10][11].

\section{Conclusion}

In short, the new media age brings opportunities to accelerate the development of sci-tech periodical industry, it also brings challenges. The competition between the sci-tech periodicals 
becomes more and more fiercer. To survive and develop, university journals must carry out reform and innovation; journal editors must change awareness, renew ideas and improve the ability; they must broaden their horizons, supplement and update professional knowledge, and improve their professional skills; they should actively participate in various forms of continuing education and professional training through the platform that new media technology offers us combined with their own journals [12]. The editors should try to learn new media technologies, increase modern editing skills, and use modern editing methods to publish university journals and realize the digitization, network and modernization of editing and publication of university journals to increase the editing and publishing efficiency, comprehensive qualities and market competition, promoting the integrative development of new media and university journals.

\section{References}

[1] M. Zhang and J. Feng: Characteristics of the New Media Age and Its Influence on China [J]. West Leather, (2016) No.4. p.114. (In Chinese)

[2] X.Y. Bai: Reflection on the Cultivation of College Journal Editors' quality in the New Era [J]. Journal of Chifeng University, Vol. 32(2016) No. 3, pp. 171-172. (In Chinese)

[3] X.P.Wei: The Existing Problems and Future Development Trend of Chinese Sci-tech Periodicals [J]. Chinese Journal of Scientific and Technical Periodicals, Vol. 12(2001) No.S, pp. 1-3. (In Chinese)

[4] Y.J.Ma: Academic Quality of University Journals and Scientific Research Level of Universities [J]. Editorial Friend, (1993) No.4, p.54. (In Chinese)

[5] T.Sun: Approaches and measures to improve the academic quality of sci-tech periodicals [J]. Acta Editologica, Vol. 28 (2016) No.3, pp. 290-292. (In Chinese)

[6] Y.H.Li and X.F.Liang: Discussion on the Social Function of Soliciting Contributions of Sci-tech Journals [J]. Chinese Journal of Scientific and Technical Periodicals, Vol.23 (2012) No.3, pp. 470-472. (In Chinese)

[7] P.He: Necessity of International Development of Biological Science Journals and Its Main Way [J]. Chinese Journal of Scientific and Technical Periodicals, Vol.14 (2003) No.S, P. 787. (In Chinese)

[8] S.X.Zhou and L.J.Liang: Usage of the Online Gathering and Editing System Benefits Sci-tech Journal Network [J]. Agricultural Research and Application, (2014) No.6, pp. 75-77. (In Chinese)

[9] R.J.Yang: On Improvement of the of Editors' Quality of Journal in the Era of Network Digitalization [J]. Journal of Suzhou University of Science and Technology (Social Science), Vol. 27(2010) No.6, pp. 94-96. (In Chinese)

[10] J.H.Zhu: Quality and Capability the Editors Should Possess in Modern Journals of Colleges [J]. Journal of Ningbo University(Natural Science \& Engineering Edition),Vol.17(2004)No.2, pp.236-239. (In Chinese)

[11] Y.Zheng: On Qualities of the Editors and the Ways to Improve Their Qualities in Colleges and Universities [J]. Journal of Inner Mongolia University for Nationalities (Social Sciences), Vol.39 (2013)No.6, pp.106-109. (In Chinese)

[12] Y.N.Shen, B.Cao and J.G.Tong: Cultivation of young editors of sci-tech periodicals in the New Period [J]. Acta Editologica, Vol.26 (2014) No.1, pp. 79-82. (In Chinese) 